\title{
Decision of National and Provincial Highway Asphalt Pavement Structure Based on Value Engineering
}

\author{
Yingwei Ren and Jingsong Shan \\ Shandong Provincial Key Laboratory of Civil Engineering Disaster Prevention and Mitigation, \\ Shandong University of Science and Technology, Qingdao 266590, China
}

Correspondence should be addressed to Jingsong Shan; cyhsjs@163.com

Received 16 November 2013; Revised 3 January 2014; Accepted 12 January 2014; Published 18 February 2014

Academic Editor: Wuhong Wang

Copyright (C) 2014 Y. Ren and J. Shan. This is an open access article distributed under the Creative Commons Attribution License, which permits unrestricted use, distribution, and reproduction in any medium, provided the original work is properly cited.

It is important that decision of asphalt pavement structure requires overall considerations of the performance and financial investment. To have asphalt pavement structure fulfilling good reliability, the asphalt pavement structure decision was researched based on value engineering theory. According to the national and provincial highway investigation data in Shandong Province during the last decade, the asphalt pavement performance attenuation rules of traffic levels and asphalt layer thicknesses were developed, and then the road performance evaluation method was presented. In addition, the initial investments, the costs of road maintenance, and middle-scale repair in a period were analyzed. For the light traffic and medium traffic example, using the value engineering method, the pavement performance and costs of which thickness varies from $6 \mathrm{~cm}$ to $10 \mathrm{~cm}$ were calculated and compared. It was concluded that value engineering was an effective method in deciding the asphalt pavement structure.

\section{Introduction}

Under the effect of traffic load and natural factors, the asphalt pavements gradually suffer damages in different forms, such as ruts, cracks, and pot holes. As the damages increasing, the functional performance of asphalt pavements decreases, which affects the traffic safety and comfort. In order to maintain a relatively high level of service performance, measures such as road maintenance and periodic maintenance are needed.

When a road is built, the functional performance is good at the beginning with little damage. At this stage, the cost of maintenance is low. As the damages increase with time, the functional performance of asphalt pavements decrease continuously, which requires more maintenance costs to keep the asphalt pavements in good condition $[1,2]$. Therefore, the choice of the asphalt pavement structure involves the factor of pavement long-term function as well as the cost during the pavement life cycle. Thus, it is an economic and technical problem. If the initial investment is large, the function is better in the later period and the maintenance cost is low. By contrast, if pavement structure with low initial investment is used, the maintenance cost will be high in the later period. Therefore, the relationship between function and cost should be considered in pavement design. If good functional performance of pavement structure is to be achieved without excessive costs, decision index should be adopted for comprehensive technical and economic evaluation.

Value engineering is the systematic application of recognized techniques that identify the function of the product or service, establish a monetary value for that function, and provide the necessary function reliably at the lowest possible cost [3]. In recently years, value engineering has been researched and widely practiced in the construction industry and become an integral part in the development of many projects [4-7]. But it was few which value engineering was used to decide asphalt pavement structure.

This paper makes choices in asphalt pavement structure by using value engineering method in the engineering economics and tries to provide guidance for highway administration department in decision making. 


\section{Theory of Value Engineering}

Value engineering (VE) is a method to achieve necessary product function with the lowest possible life-cycle cost. Expression of value engineering is as follow:

$$
V=\frac{F}{C}
$$

where $V$ is value; $F$ is function; $C$ is cost.

Figure 1 shows the relationship between function and cost. $C_{1}$ indicates the initial construction cost and $C_{2}$ indicates the cost in the process of use. The relationship between $C_{1}$ and $C_{2}$ can be seen from this figure. Product function will increase either by increasing $C_{1}$ or decreasing $C_{2}$. Product function will decrease either by decreasing $C_{1}$ or increasing $C_{2}$. The purpose of value engineering is to check and give consideration to both costs and to figure out the optimum point of function so as to minimize the overall cost $(C)$ [8].

According to value engineering theory, the methods of improving the value are as follows:

(1) reducing the cost while improving the function;

(2) keeping the function unchanged while reducing the cost;

(3) keeping the cost unchanged while increasing the function;

(4) increasing the cost slightly while increasing the function greatly;

(5) reducing the function slightly while reducing the cost greatly. The reduced function should be within the users' permission.

As is shown in formula (1), the pavement is regarded as a product with relatively long life time and if reasonable pavement structure is to be achieved, function and cost should be taken into account, so as to achieve high function at relatively low cost. Therefore, applying the value engineering method to choose the asphalt pavement structure requires determinations of both functional performance evaluation and the cost calculation method, which are shown, respectively, in the sections below.

\section{Performance Evaluation Method}

3.1. Pavement Performance Model. The asphalt pavement performance can be expressed by single index, such as crack rate, and amount of ruts. It can also be expressed by comprehensive index such as PCI (Pavement Condition Index) and RQI (Riding Quality Index). A single index can directly show the severity and development of a single damage. So the maintenance measures can be established with more pertinence. Comprehensive index, synthesized with many single indexes, can reflect the service condition within the whole road at a certain time. This paper uses PCI (Pavement Condition Index) to evaluate the functional performance of pavement.

The asphalt performance is affected by many factors, such as the asphalt pavement layer thickness, the thickness and

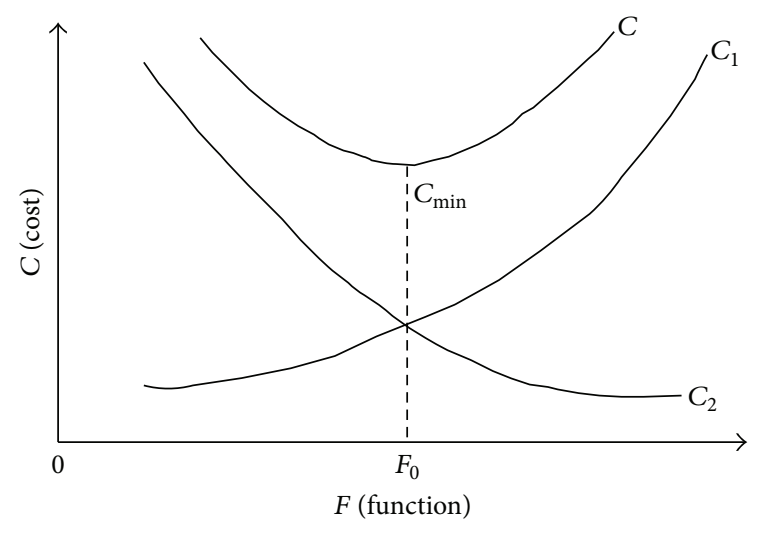

FIGURE 1: Relationship between function and cost.

strength of base layer, the subgrade strength, the natural environment, and the automobile load. And the quality of construction also has a direct impact on pavement performance. Therefore, the asphalt pavement performance evaluation is a complicated task. And asphalt pavement performance evaluation is related to highway investment decision, design, and later maintenance, so it is a necessary task. In the 1960s, American Association of State Highway and Transportation Officials (AASHTO) established the pavement performance attenuation equation according to the experimental data and Pavement Service Index (PSI), which is one of the first road performance models $[9,10]$. The model is

$$
\mathrm{PSI}=\mathrm{PSI}_{0}-\left(\mathrm{PSI}_{0}-\mathrm{PSI}_{t}\right)\left(\frac{\mathrm{ESAL}}{\mathrm{ESAL}_{t}}\right)^{\beta}
$$

Based on investigation, the $\mathrm{PSI}_{0}$ at the initial state of the pavement and the $\mathrm{PSI}_{t}$ at the critical state as well as the accumulated equal single axle load $\mathrm{ESAL}_{t}$ near the collapse state are firstly determined in this method. And the PSI value is determined according to the accumulated equal single axle load $\mathrm{ESAL}_{t}$ at a certain time.

During the past decades, many people started to do related research on the expression forms of pavement function. Professor Sun Lijun put forward the expression form of Pavement Condition Index (PCI), as is shown in formula (3), which can simulate the pavement function attenuation law through the changes in $\alpha$ and $\beta$ value [11]. Factors such as the pavement layer thickness, the surface deflection, the accumulated equal single axle load, and the natural environment should be taken into consideration when determining the $\alpha$ and $\beta$ value, thus to make it become a comprehensive asphalt function model [12-14]. Based on the national and provincial highway research data in Shandong Province, the value of $\alpha$ and $\beta$ is established with this model in this paper:

$$
\mathrm{PCI}=\mathrm{PCI}_{0}\left\{1-\exp \left[-\left(\frac{\alpha}{y}\right)^{\beta}\right]\right\} .
$$

The newly built and rebuilt asphalt pavement layer thicknesses in China are mostly $6 \mathrm{~cm}, 8 \mathrm{~cm}$, and $10 \mathrm{~cm}$, with $7 \mathrm{~cm}$ and $9 \mathrm{~cm}$ accounting for the minority. When deciding the 
TABLE 1: Questionnaire of asphalt pavement condition of national and provincial highway.

\begin{tabular}{|c|c|c|c|c|c|c|}
\hline Number & $\begin{array}{l}\text { Asphalt pavement } \\
\text { layer thickness }\end{array}$ & $\begin{array}{l}\text { Base layer type and } \\
\text { thickness }\end{array}$ & $\begin{array}{l}\text { Damages start } \\
\text { time }\end{array}$ & $\begin{array}{c}\text { Years of } \\
\text { intermediate } \\
\text { maintenance }\end{array}$ & $\begin{array}{l}\text { Large vehicle } \\
\text { volume }\end{array}$ & Notes \\
\hline \multicolumn{7}{|l|}{1} \\
\hline \multicolumn{7}{|l|}{2} \\
\hline 3 & & & & & & \\
\hline
\end{tabular}

$\alpha$ and $\beta$ value, asphalt pavement is divided by thickness, namely $6 \mathrm{~cm}, 8 \mathrm{~cm}$, and $10 \mathrm{~cm}$. And functional performances are counted and analyzed under different thickness groups. In each group, traffic load is considered as the main factor. Because of inadequate construction budget, observation stations are not equipped with axle load weighing appliances, so only traffic flow can be obtained according to vehicle types in different months. According to vehicle classification, large- and medium-sized trucks and motor buses have largely effects on pavement damages than other vehicles; thus they are considered in this research. The data collected are listed in Table 1.

3.2. The Solving Process of $\alpha$ and $\beta$ Values. The determination of $\alpha$ and $\beta$ is very important to expressing pavement function through formula (3). According to the national and provincial highway research data in Shandong Province, formula (4) can be obtained by inputting PCI of different pavements $\left(a_{1}\right.$ and $a_{2}$ represent different years) in formula (3):

$$
\mathrm{PCI}_{1}=\mathrm{PCI}_{0}\left\{1-\exp \left[-\left(\frac{\alpha}{a_{1}}\right)^{\beta}\right]\right\},
$$

where $\mathrm{PCI}_{1}$ represents $\mathrm{PCI}$ value after $a_{1}$ years and $\mathrm{PCI}_{2}$ represents PCI value after $a_{2}$ years. Supposing the initial pavement condition is good and the PCI is 100, then formula (3) can be simplified into formula

$$
\begin{aligned}
& \ln A_{1}=-\left(\frac{\alpha}{a_{1}}\right)^{\beta}, \\
& \ln A_{2}=-\left(\frac{\alpha}{a_{2}}\right)^{\beta},
\end{aligned}
$$

where $A_{1}=1-\mathrm{PCI}_{1} / 100, A_{2}=1-\mathrm{PCI}_{2} / 100$.

By taking logarithm on both sides of the formula (5), formula (6) is obtained:

$$
\begin{gathered}
a=\frac{\ln \left(\ln \left(1 / A_{1}\right)\right) \times \ln a_{2}-\ln \left(\ln \left(1 / A_{2}\right)\right) \times \ln a_{1}}{\ln \left(\ln \left(1 / A_{1}\right)\right)-\ln \left(\ln \left(1 / A_{2}\right)\right)}, \\
\beta=\frac{\ln \left(\ln \left(1 / A_{1}\right)\right)-\ln \left(\ln \left(1 / A_{2}\right)\right)}{\ln a_{2}-\ln a_{1}} .
\end{gathered}
$$

$\alpha$ and $\beta$ can be obtained through formula (6). When the asphalt pavement layer thickness is $10 \mathrm{~cm}, \alpha$ and $\beta$ curves are drawn in Figure 2 considering different daily large vehicle volume. After comparison in different fitting methods, the power exponent form is used, as the fitting curve is consistent with the variation trend of measured data. The relationship is established between $\alpha, \beta$ and the daily large vehicle volume per lane, which is listed in formula

$$
\begin{aligned}
& \alpha=98.6 Q^{-0.369}, \\
& \beta=4.469 Q^{-0.267} .
\end{aligned}
$$

Using the same method, relations between $\alpha$ and $\beta$ under different asphalt pavement layer thicknesses $(6 \mathrm{~cm}$ and $8 \mathrm{~cm})$ can be established. Take asphalt pavement layer thickness $(h)$ as a variable and use $h$ to express coefficients and exponents in the relation of $\alpha$ and $\beta$. Formula (8) is as follows:

$$
\begin{aligned}
& \alpha=1431 h^{-1.164} Q^{0.051 h-0.868}, \\
& \beta=0.171 e^{0.323 h} Q^{-0.0465 h+0.2} .
\end{aligned}
$$

For instance, supposing the daily large vehicle volume per lane is $1000, \alpha$ and $\beta$ can be obtained firstly through formula (8), then putting them into formula (3) and PCI value of the road will be got. The PCI curve with years is drawn in Figure 3 considering the thickness variations of asphalt layer. As can be seen from the figure, when the asphalt pavement layer thickness changes from $6 \mathrm{~cm}$ to $10 \mathrm{~cm}$, the age of PCI down to 60 increases from 5 to 9 years. This implies that under the traffic level, the deteriorating rate is quicker when asphalt thickness is thinner, and to improve pavement property, asphalt thickness should be increased appropriately.

\subsection{Performance Evaluation Method of Asphalt Pavement} Structure. According to value engineering, pavement function index is needed when analyzing the value of different pavement schemes. The curve in Figure 3 can express the functional performance attenuation law of asphalt pavement with different layer thicknesses, but it cannot directly make comprehensive comparison through this PCI curve. Therefore, pavement performance is expressed by the area under the PCI curve in Figure 4. Before calculating the area under the PCI curve, the lowest acceptable level is determined firstly according to pavement rank and function requirements, and then, integration method is used to calculate the area $S_{d}$.

\section{Cost Calculation}

After construction completion, the highways need repeated maintenance, overlay and rebuilt during the life time. It is obvious that highway engineering needs constant investment on maintenance during more than ten years or even decades, 


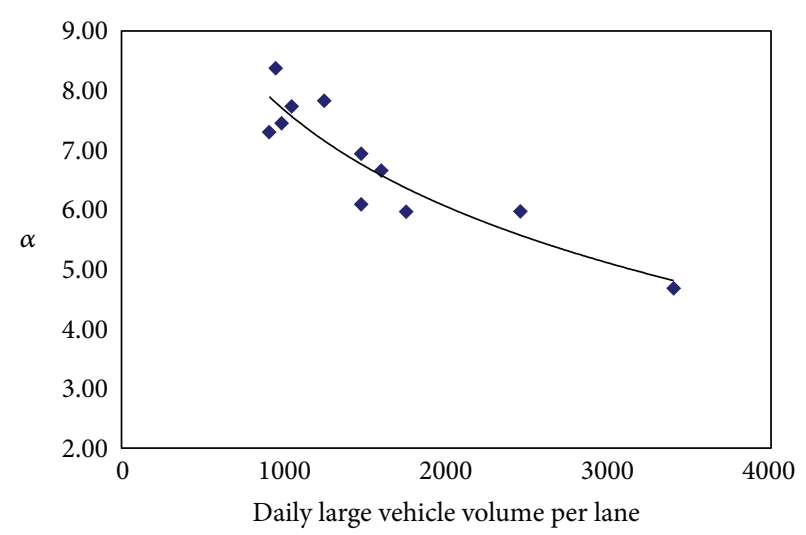

(a) Relationship between $\alpha$ and daily large vehicle volume per lane

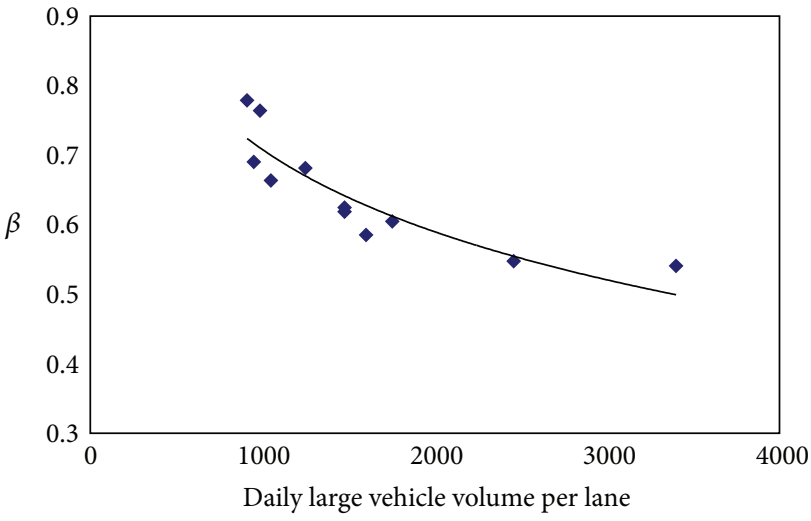

(b) Relationship between $\beta$ and daily large vehicle volume per lane

FIGURE 2: Thickness of asphalt pavement layer is $10 \mathrm{~cm}$.

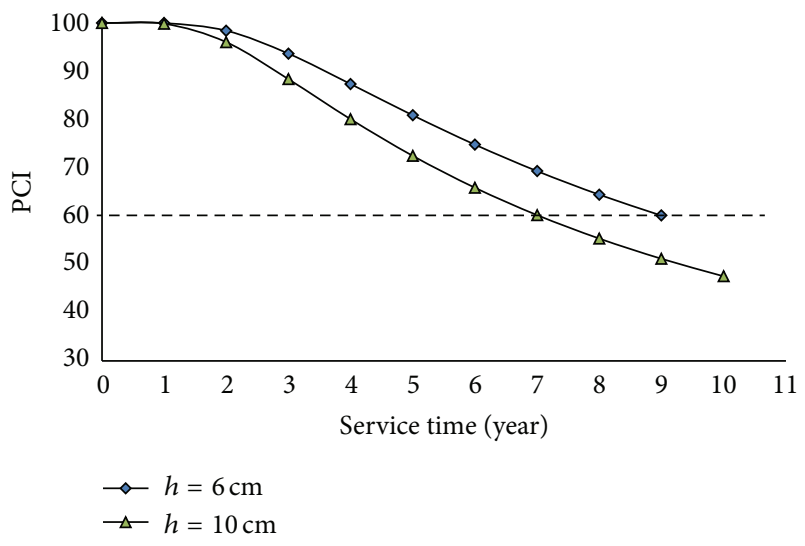

FIgURE 3: Regularity of PCI with years.

which should not be underestimated. When considering pavement cost, except initial construction cost, the maintenance cost should be considered integrally. In the 1960s, American Association of State Highway and Transportation Officials (AASHTO) put forward the concept of life-cycle cost. In 1986 and 1993, AASHTO Pavement Design Guide was published twice, both of which actively advocated the adoption of life-cycle cost analytical method. In 1998, American Association of State Highway and Transportation Officials issued the standard, which also advocated the adoption of life-cycle cost analytical method when making decisions on highway investment [15-17]. In 2008, transportation department in the state of Mississippi conducted an investigation with 21 states. Among them, 18 states, including Alabama and New Jersey, applied life-cycle cost analytical method when making decisions on highway investment. In China, Professor Yao Zukang along with his research group did some research in light of China's conditions, and the results have not been applied in decision making of highway structures yet.

Life-cycle cost includes initial construction cost, maintenance cost, overlay rebuilt cost, and user cost. As our country fall behind developed counties in the users' cost research

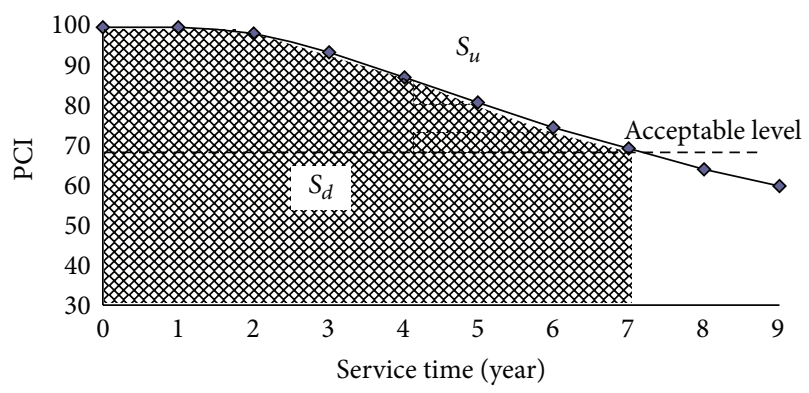

Figure 4: Area under PCI curve.

field, there is no suitable calculation model for users' cost. In this paper, users' cost is not included in life-cycle cost. So life-cycle cost includes road management department's investment during the life cycle, namely, initial construction cost, maintenance cost, and overlay rebuilt cost.

(1) Maintenance Cost. The calculation of maintenance cost adopts the computation model by Tongji University, as is show in formula

$$
\mathrm{MC}_{i}=a+b \times 10^{-6}\left(100-\mathrm{PCI}_{i}\right) \times \mathrm{AADT}_{i},
$$

where $\mathrm{AADT}_{i}$ is $\mathrm{ADT}$ (Average Daily Traffic) in the year of $i$; $\mathrm{PCI}_{i}$ is road condition index in the year of $i$; and $\mathrm{MC}_{i}$ is maintenance cost in the year of $i\left(\right.$ Yuan $\left./ \mathrm{m}^{2}\right)$.

(2) Salvage Value. At the end of the analysis period, if the pavement functional performance is still above the lowest acceptable level and roads can be passed through, the current value left is called the salvage value. As is shown in formula (10), the salvage value is modeled as a linear regression function, in which the salvage value reduces linearly with age, without being considered in the case of the nonlinear reduction of the pavement functional performance. Therefore, in this paper, the computation strategy is conducted in which the area under the PCI curve is computed to indicate the salvage value based on formula (11), as is shown in Figure 5. 


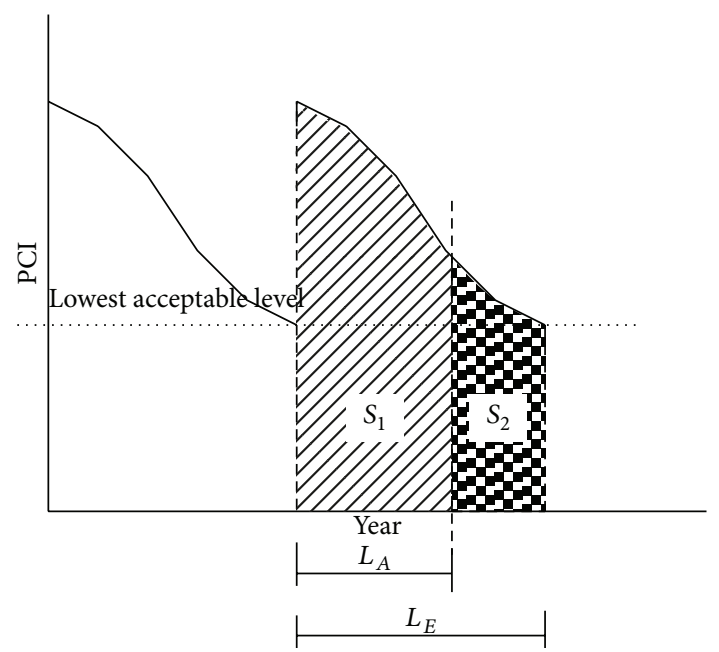

Figure 5: Pavement salvage value.

Consider

$$
S_{v}=\left(1-\frac{L_{A}}{L_{E}}\right) C_{r}
$$

where $S_{v}$ is salvage value; $C_{r}$ is the last intermediate maintenance overlay cost in analysis period; $L_{E}$ is years between the last time maintenance and the end of life time; $L_{A}$ is years between the last maintenance time and the end of analysis period.

Consider

$$
S_{v}=\left(1-\frac{S_{1}}{S_{1}+S_{2}}\right) C_{r},
$$

where $S_{1}$ is area under curve $L_{A}$ and $S_{2}$ is area under curve $L_{E}$.

(3) Present Value of Cost. Various costs in the analysis period are discounted into present value according to a certain discount rate. Therefore, economic efficiency of different schemes can be compared through the uniform present value. Capital flow in road investment is shown in Figure 6.

One has

$$
P_{0}=C_{0}+\sum_{i=1}^{n} f_{i}\left(\mathrm{MC}_{i}+\mathrm{RC}_{i}\right)-f_{n} S_{v},
$$

where $P_{0}$ is total cost of present value; $C_{0}$ is the initial construction cost; $\mathrm{MC}_{i}$ is the maintenance cost in the year of $i \mathrm{MC}_{i}$ is the intermediate maintenance overlay cost in the year of $i$; $S_{v}$ is salvage value; $f_{i}, f_{n}$ is discount rate in the year of $I$ and in the year of $n$, respectively.

\section{Pavement Structure Decision Based on Value Engineering}

According to the proceeding discussion, the analysis of pavement functional performance is vital when making decisions of pavement structure based on value engineering. PCI curve

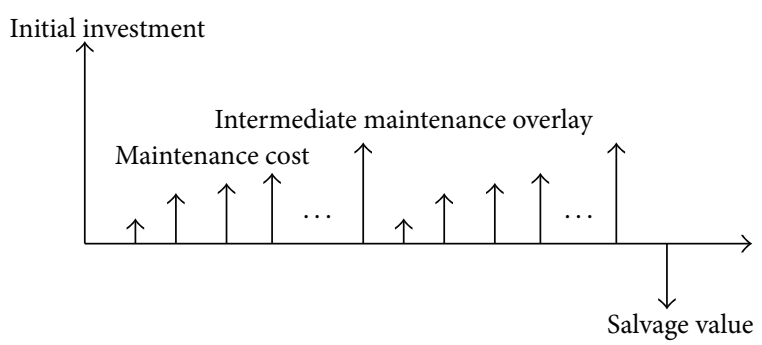

FIGURE 6: Capital flow in road investment.

is closely related to pavement structure function evaluation, daily maintenance cost, intermediate maintenance time, and salvage value calculation. Therefore, PCI curve should be established in the first place when making decisions of pavement structure based on value engineering, and on this basis, cost is further analyzed. Figure 7 is the flow chart of value calculation.

Take the example of light traffic and medium traffic of national and provincial asphalt pavement in Shandong. Supposing daily large vehicle volume per lane is 600 vehicles in light traffic which has average daily traffic 6000 vehicles, large vehicle volume per day per lane is 600 vehicles in medium traffic which has average daily traffic 10000 vehicles. Suppose the asphalt pavement layer thickness is $6 \mathrm{~cm}$ to $10 \mathrm{~cm}$ and the base layer is double-layered cement stabilized crushed stone base. Comparison of different asphalt pavement layer thicknesses is made according to value engineering, which is followed below.

Based on the PCI formula above, the PCI curve of this case where the asphalt pavement layer thicknesses are $10 \mathrm{~cm}$, $8 \mathrm{~cm}$, and $6 \mathrm{~cm}$ is drawn in Figure 8, respectively. The analysis period is 15 years, during which asphalt pavement of $6 \mathrm{~cm}$ needs twice intermediate overlay, while asphalt pavement of $8 \mathrm{~cm}$ and $10 \mathrm{~cm}$ need only once. The area under PCI curve is calculated through integration method, so as to express the function of different asphalt pavements.

Initial investment is determined according to calculation method of life-cycle cost and based on asphalt pavement price in Shandong in 2010. Supposing the price inflation rate is $5 \%$ and the discount rate is $10 \%$, the total daily maintenance cost on a yearly basis and the intermediate maintenance costs are calculated in different asphalt pavement layer thicknesses and are converted into present value. When the asphalt pavement layer thickness is $10 \mathrm{~cm}$ under light traffic, the calculation process of costs is listed in Table 2. Other costs with different thicknesses are calculated in the same way and are listed in Table 3.

As can be seen from Table 3, from the perspective of function, asphalt pavement's performance is best when the layer thickness is $10 \mathrm{~cm}$ under light traffic, which is followed by $8 \mathrm{~cm}$ and $6 \mathrm{~cm}$. However, from the perspective of life-cycle cost, asphalt pavement with layer thickness of $10 \mathrm{~cm}$ is the most expensive and it is relatively cheaper when the layer thickness is $8 \mathrm{~cm}$ and $6 \mathrm{~cm}$. This is caused by the high initial investment (layer thickness is $10 \mathrm{~cm}$ ) and the money saved by maintenance investment and intermediate maintenance cost 


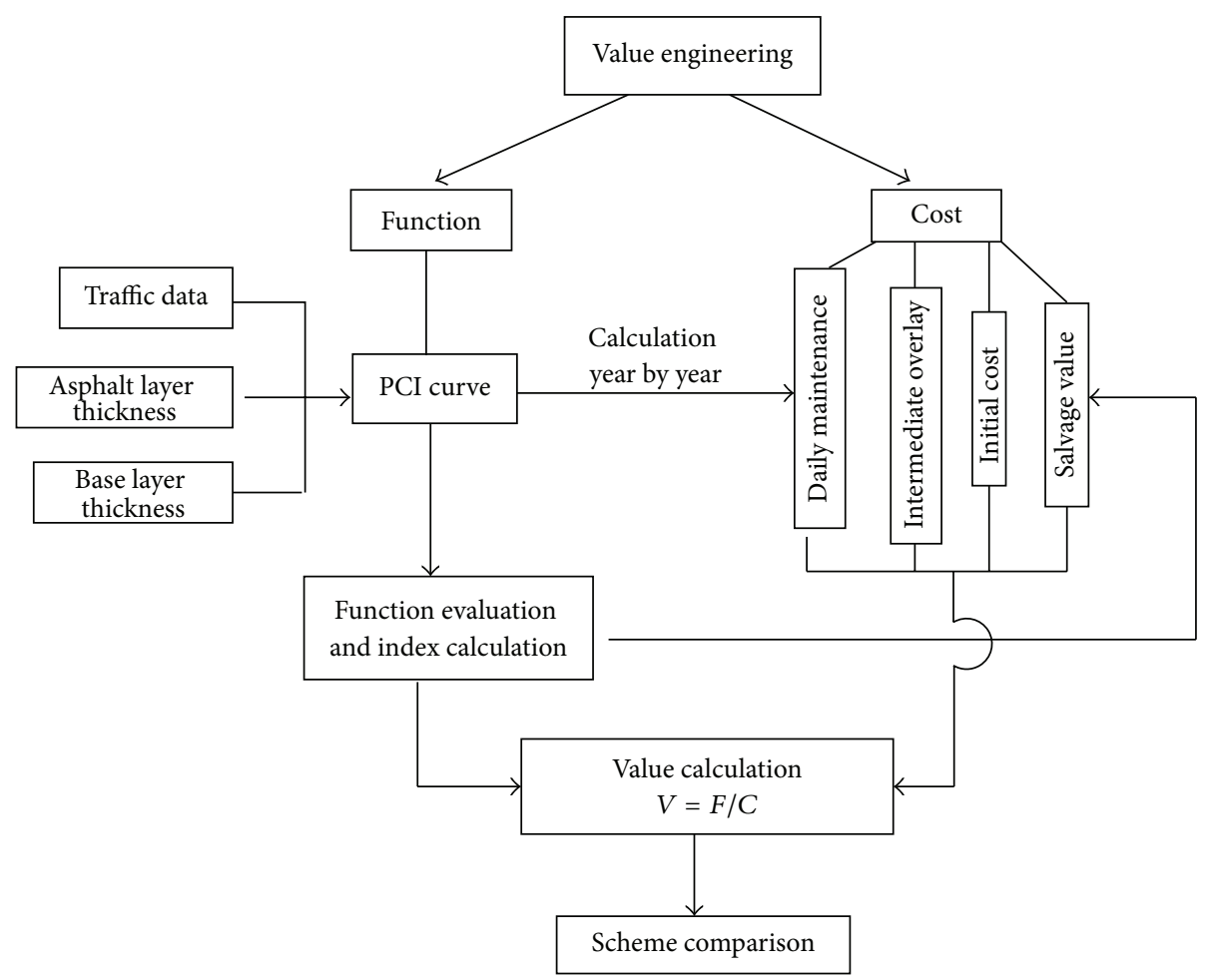

FIGURE 7: Value engineering calculation procedure.

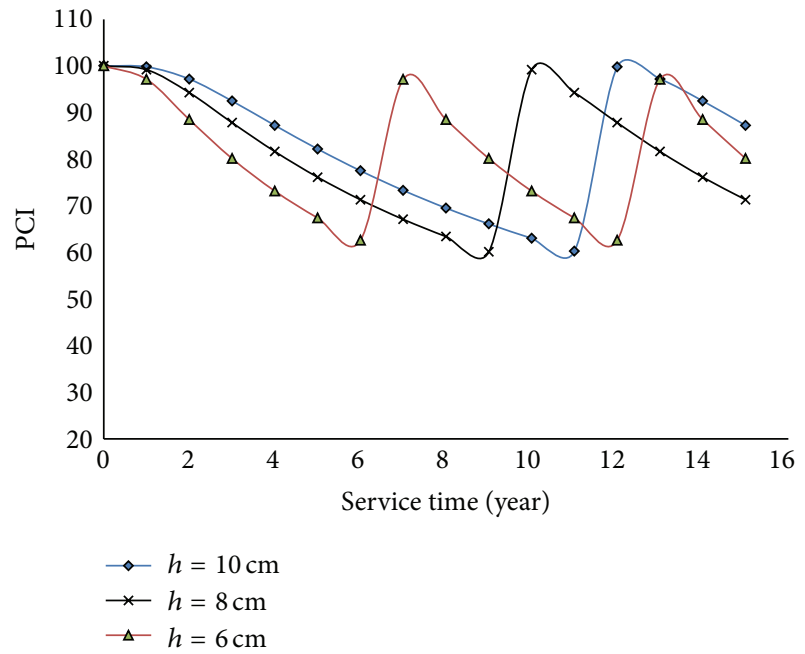

FIGURE 8: PCI curves of different asphalt pavement layer thicknesses.

cannot make up for the high initial cost. So in the case of light traffic, the asphalt pavement is the most suitable when the layer thickness is $8 \mathrm{~cm}$.

The functional performance is the best when the layer thickness is $10 \mathrm{~cm}$ under medium traffic, which is followed by $8 \mathrm{~cm}$ and $6 \mathrm{~cm}$. The life-cycle cost is relatively high when the layer thickness is $10 \mathrm{~cm}$ and $6 \mathrm{~cm}$, the life-cycle cost is relatively low when the layer thickness is $8 \mathrm{~cm}$, which illustrates the fact that thin layer thickness of asphalt pavement can accelerate the damage speed so as to largely increase the maintenance cost. It can be concluded that the value is lowest when the asphalt pavement layer thickness is $6 \mathrm{~cm}$ and it is economically more reasonable when the asphalt pavement layer thickness is $8 \mathrm{~cm}$ or $10 \mathrm{~cm}$. With the increase in traffic, namely, when the daily large-sized vehicles volume per lane goes to over 1200, asphalt pavement has better functional performance with layer thickness over $10 \mathrm{~cm}$.

\section{Conclusions}

In this paper the theory of value engineering is applied to the decision-making process of the national and provincial highway asphalt pavement structures to find the best point of pavement performance and economic investment. The decision of asphalt pavement structure based on value engineering is reliable and economic. The main achievements are as follows.

(1) According to national and provincial highway investigation data in Shandong Province during the last decade, the relationship is established between $\alpha, \beta$ and the two factors, namely, the asphalt pavement layer thickness and the daily large-sized vehicle volume per lane. The attenuation law of national and provincial highway asphalt pavement is easily analyzed with these two parameters $\alpha$ and $\beta$.

(2) Based on the PCI attenuation curve, the pavement performance is expressed by the area under the PCI curve and the calculation method of pavement performance is established, which can be applied to pavement performance 
TABLe 2: Life-cycle cost $\left(\right.$ Yuan $\left./ \mathrm{m}^{2}\right)$.

\begin{tabular}{|c|c|c|c|c|c|c|c|c|}
\hline $\begin{array}{l}\text { Service life } \\
\text { period }\end{array}$ & PCI & $\begin{array}{c}\text { Initial } \\
\text { investment }\end{array}$ & $\begin{array}{l}\text { Maintenance } \\
\text { investment }\end{array}$ & $\begin{array}{c}\text { Intermediate } \\
\text { maintenance and } \\
\text { overlay } \\
\end{array}$ & $\begin{array}{l}\text { Salvage } \\
\text { value }\end{array}$ & $\begin{array}{l}\text { Present value } \\
\text { of } \\
\text { maintenance } \\
\end{array}$ & $\begin{array}{c}\text { Present value of } \\
\text { intermediate } \\
\text { maintenance overlay }\end{array}$ & $\begin{array}{l}\text { Present value of } \\
\text { salvage value }\end{array}$ \\
\hline 0 & 100.00 & 100 & & & & & & \\
\hline 1 & 99.79 & & 1.01 & & & 0.94 & & \\
\hline 2 & 97.18 & & 1.17 & & & 1.00 & & \\
\hline 3 & 92.47 & & 1.45 & & & 1.15 & & \\
\hline 4 & 87.23 & & 1.77 & & & 1.30 & & \\
\hline 5 & 82.17 & & 2.07 & & & 1.41 & & \\
\hline 6 & 77.50 & & 2.35 & & & 1.48 & & \\
\hline 7 & 73.29 & & 2.60 & & & 1.52 & & \\
\hline 8 & 69.50 & & 2.83 & & & 1.53 & & \\
\hline 9 & 66.09 & & 3.03 & & & 1.52 & & \\
\hline 10 & 63.01 & & 3.22 & & & 1.49 & & \\
\hline 11 & 60.24 & & 3.39 & & & 1.45 & & \\
\hline 12 & 99.79 & & 1.01 & 71.8 & & 0.40 & 28.5 & \\
\hline 13 & 97.18 & & 1.17 & & & 0.43 & & \\
\hline 14 & 92.47 & & 1.45 & & & 0.49 & & \\
\hline \multirow[t]{3}{*}{15} & 87.23 & & 1.77 & & -41.29 & 0.56 & & -13.02 \\
\hline & $\begin{array}{l}\text { Total } \\
\text { present } \\
\text { value }\end{array}$ & 100 & & & & 16.67 & 28.5 & -13.02 \\
\hline & $\begin{array}{l}\text { Life-cycle } \\
\text { cost }\end{array}$ & & & & 132.15 & $m^{2}$ & & \\
\hline
\end{tabular}

TABLE 3: Calculation of value.

\begin{tabular}{|c|c|c|c|c|}
\hline $\begin{array}{l}\text { Number of large-sized vehicles } \\
\text { per lane per day }\end{array}$ & & $h=10 \mathrm{~cm}$ & $h=8 \mathrm{~cm}$ & $h=6 \mathrm{~cm}$ \\
\hline \multirow[t]{3}{*}{ ( } & function (area covered by PCI) & 1265 & 1239 & 1213 \\
\hline & Life-cycle cost & 132.15 & 122.27 & 122.94 \\
\hline & value (function/cost) & 9.57 & 10.13 & 9.87 \\
\hline \multirow{3}{*}{1000} & function (area covered by PCI) & 1228 & 1190 & 1173 \\
\hline & Life-cycle cost & 153.28 & 145.67 & 158.77 \\
\hline & value (function/cost) & 8.01 & 8.17 & 7.39 \\
\hline
\end{tabular}

evaluation and comparison between different pavement structures.

(3) In the example of light traffic and medium traffic of national and provincial highway, value engineering theory is applied to analyze the technicality and economic efficiency of asphalt pavement with different layer thicknesses $(10 \mathrm{~cm}$, $8 \mathrm{~cm}$, and $6 \mathrm{~cm}$ ). It can be concluded that under light traffic, the value is the highest when the layer thickness is $8 \mathrm{~cm}$ and the value is the lowest when the layer thickness is $10 \mathrm{~cm}$. Under light traffic, the value is maximized in the case of the asphalt pavement layer thickness at $8 \mathrm{~cm}$ and minimized at $10 \mathrm{~cm}$. However, under medium traffic, the value is maximized when the asphalt pavement layer thickness equals $9 \mathrm{~cm}$ and minimized when it is $6 \mathrm{~cm}$. Through the analysis of this example, it can be indicated that using engineering value theory is an effective way in deciding reasonable pavement structures.

(4) When deciding pavement structures, the schemes with the highest value or closer to the highest value should be selected and it is not appropriate to choose the schemes with the highest function or the lowest life-cycle cost. With consideration of the project investment conditions, schemes with the lowest economic cost as well as satisfying the pavement functions should be chosen.

\section{Conflict of Interests}

The authors declare that there is no conflict of interests regarding the publication of this paper. 


\section{Acknowledgments}

This research was funded by "Shandong Provincial Natural Science foundation (no. ZR2011EEQ027)" and "Key Laboratory of Road and Traffic Engineering of the Ministry of Education, Tongji University (no. 201002)". The authors gratefully acknowledge their support.

\section{References}

[1] T. F. Fwa and K. C. Sinha, "Pavement performance and life-cycle cost analysis," Journal of Transportation Engineering, vol. 117, no. 1, pp. 33-46, 1991.

[2] Federal Highway Administration, Life-Cycle Cost Analysis in Pavement Design-in Search of Better Investment Decisions, Pavement Division Interim Technical Bulletin, FHWA, US DOT, Washington, DC, USA, 1998.

[3] Q. S. Liu and W. S. Shen, Value Engineering Management and Practice, Beyond Business Administration Consultant Co., 1995.

[4] L. D. Miles, Techniques of Value Analysis and Engineering, McGraw-Hill, New York, NY, USA, 2nd edition, 1972.

[5] A. Omigbodun, "Value engineering and optimal building projects," Journal of Architectural Engineering, vol. 7, no. 2, pp. 40-43, 2001.

[6] S. Assaf, O. A. Jannadi, and A. Al-Tamimi, "Computerized system for application of value engineering methodology," Journal of Computing in Civil Engineering, vol. 14, no. 3, pp. 206214, 2000.

[7] X. Mao, X. Zhang, and S. M. Abourizk, "Enhancing value engineering process by incorporating inventive problem-solving techniques," Journal of Construction Engineering and Management, vol. 135, no. 5, pp. 416-424, 2009.

[8] D. L. Younker, Value Engineering Analysis and Methodology, Marcel-Dekker, New York, NY, USA, 2003.

[9] AASHTO, AASHTO Guide For Design of Pavement Structures. Part II, Washington, DC, USA, 1993.

[10] SHRP, "Evaluation of the AASHTO design equations and recommended improvements," Tech. Rep. SHRP-P-394, Washington, DC, USA, 1994.

[11] S. Lijun and L. Liping, "Performance-based whole-life design method for asphalt pavement," Journal of Tongji University, vol. 31, pp. 832-837, 2003.

[12] S. Labi, Impact of highway pavement maintenance activities [Ph.D. thesis], School of Civil Engineering, Purdue University, West Lafayette, Ind, USA, 2001.

[13] S. Labi and K. C. Sinha, "Grassroots perspectives of pavement preventive maintenance-a state-of-practice survey in Indiana," International Journal of Pavements, vol. 1, no. 3, pp. 44-57, 2002.

[14] S. Labi and K. C. Sinha, "Measures of short-term effectiveness of highway pavement maintenance," Journal of Transportation Engineering, vol. 129, no. 6, pp. 673-683, 2003.

[15] FHWA, "Life-cycle cost analysis in pavement design-in search of better investment decisions," Tech. Rep. FHWA-SA-98-079, Federal Highway Administration, U.S. Department of Transportation, Washington, DC, USA, 1998.

[16] FHWA, Life-Cycle Cost Analysis Primer, US Department of Transportation, Washington, DC, USA, 2002.

[17] G. Lamptey, M. Z. Ahmad, S. Labi, and K. C. Sinha, "Life-cycle cost analysis for INDOT pavement design procedures," Tech. Rep. FHWA/IN/JTRP-2005/28, Joint Transportation Research Program, 2005. 


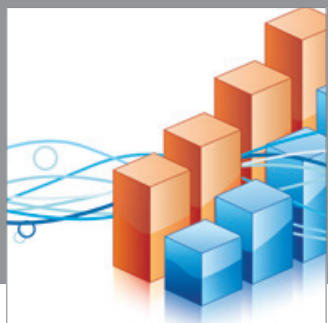

Advances in

Operations Research

mansans

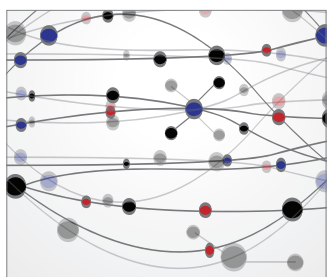

The Scientific World Journal
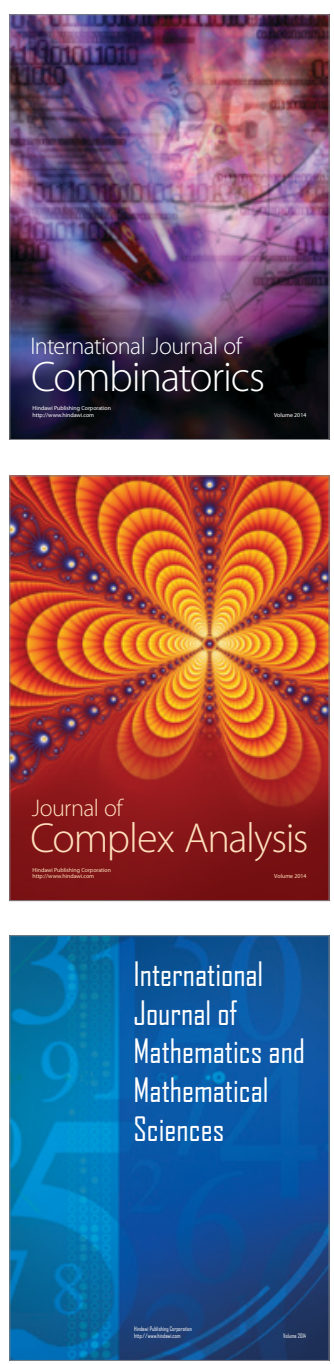
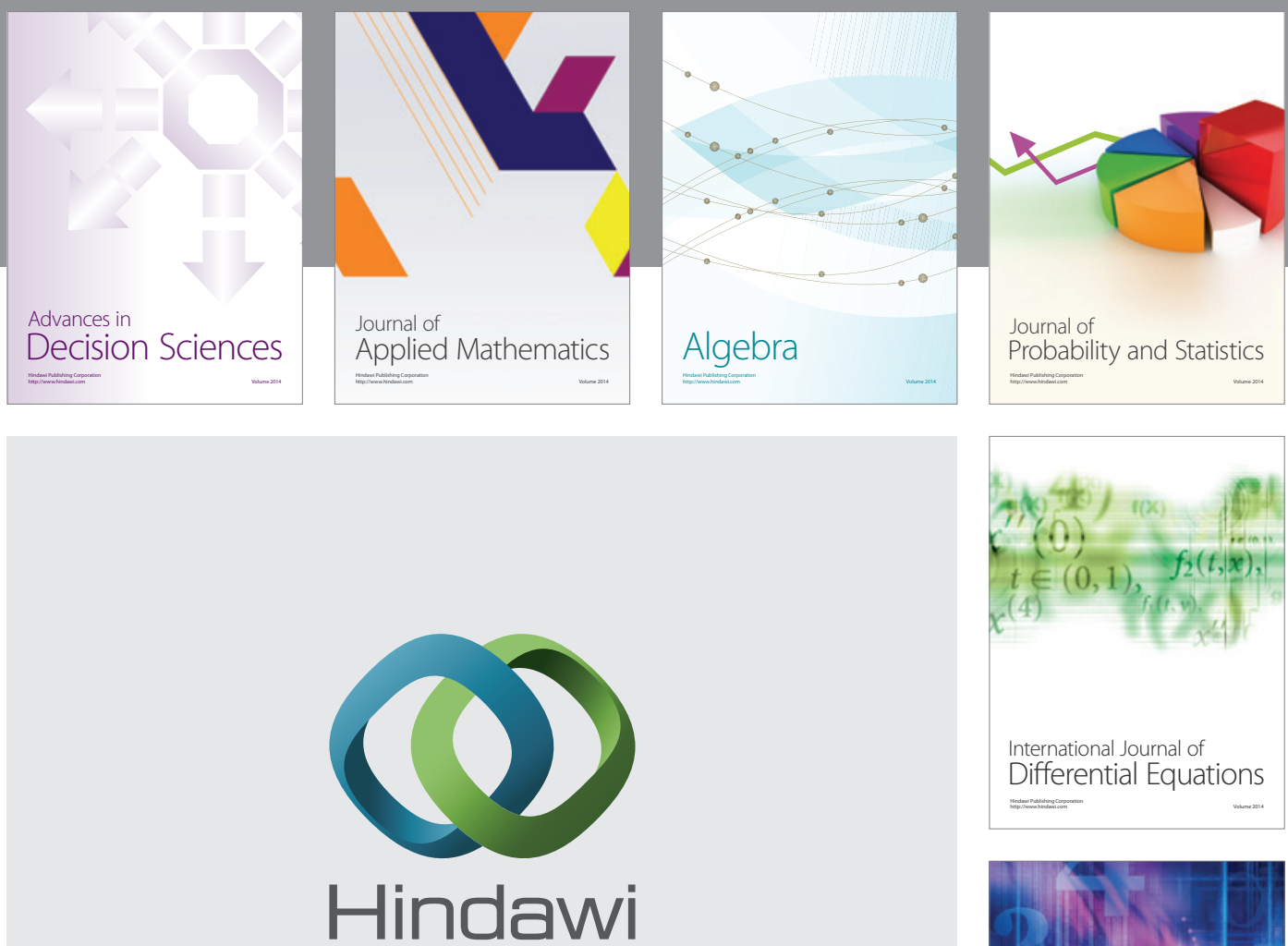

Submit your manuscripts at http://www.hindawi.com
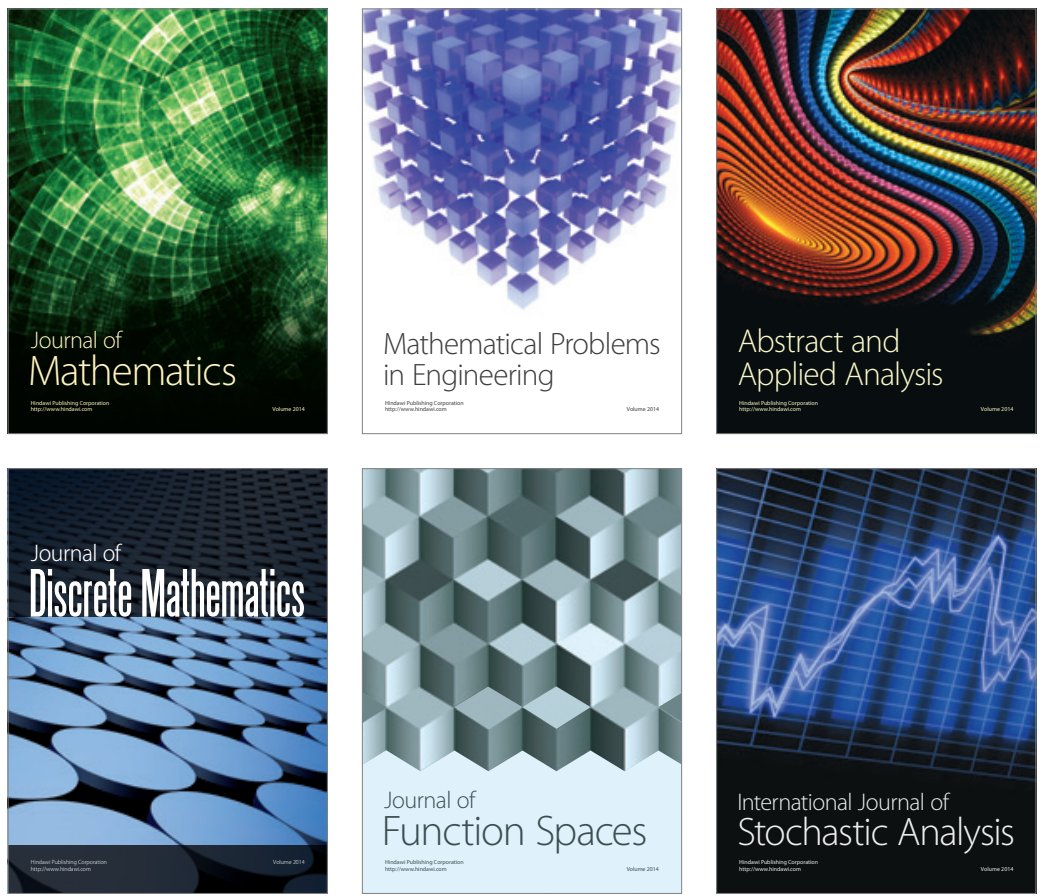

Journal of

Function Spaces

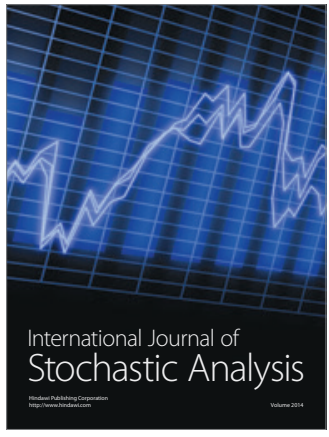

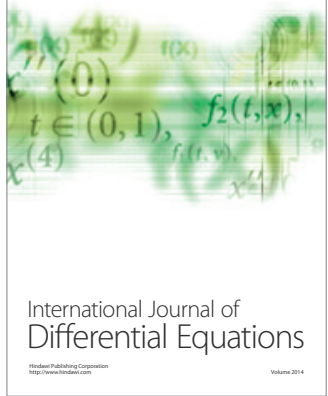
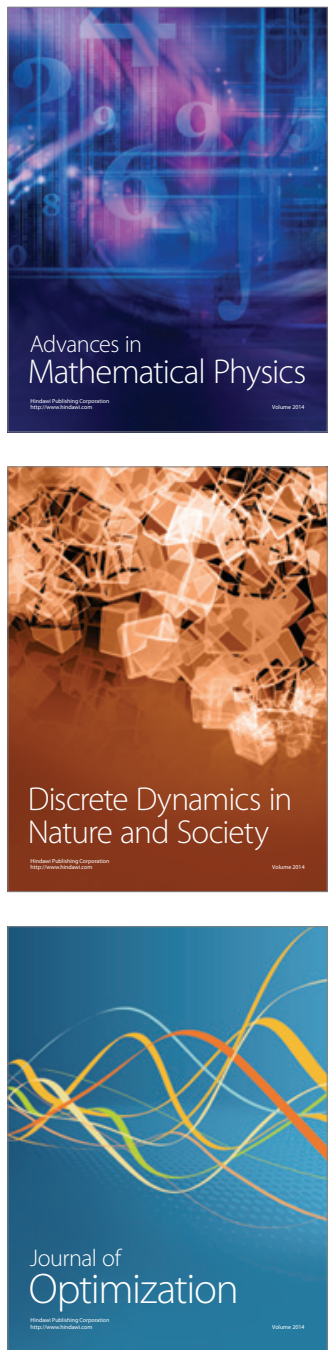